\title{
Breakdown of immunity to Nippostrongylus brasiliensis in lactating rats
}

\author{
Jos G. M. Houdijk ${ }^{1 *}$, Neil S. Jessop ${ }^{2}$, David P. Knox ${ }^{3}$ and llias Kyriazakis ${ }^{1}$ \\ ${ }^{1}$ Animal Nutrition and Health Department, Scottish Agricultural College, West Mains Road, \\ Edinburgh EH9 3JG, UK \\ ${ }^{2}$ Institute of Ecology and Resource Management, The University of Edinburgh, West Mains Road, \\ Edinburgh EH9 3JG, UK \\ ${ }^{3}$ Moredun Research Institute, Pentland Science Park, Bush Loan, Penicuik EH26 OPZ, UK
}

(Received 27 November 2002 - Revised 10 April 2003 - Accepted 23 June 2003)

\begin{abstract}
The nutritional basis of breakdown of immunity to parasites may be addressed in a rodent model. We hypothesized that lactating rats would show a breakdown of immunity to Nippostrongylus brasiliensis, and that this breakdown of immunity would be sensitive to protein supply. Rats were immunized with 1600 infective $N$. brasiliensis larvae and subsequently mated. During lactation, these rats were offered foods with 90 (low protein; LP) or 210 (high protein, HP) g crude protein $(\mathrm{N} \times 6 \cdot 25) / \mathrm{kg}$ and re-infected with 400, 800 or 1600 larvae on day 2 postparturition. Immunized non-reproducing rats were offered a food containing $60 \mathrm{~g}$ crude protein $/ \mathrm{kg}$ and re-infected with 1600 larvae. Seven days after secondary infection, lactating rats had more adult nematodes in their small intestine and nematode eggs in their colon contents than the non-reproducing rats. Protein supply did not affect worm or egg counts, although LP rats carried relatively more female nematodes than the HP rats. All lactating rats had lower intakes than expected from previous studies using similar nutritional protocols. This may have resulted in insufficient protein supply, even for the HP rats, and this could explain the absence of effects of protein supply on egg and worm counts. We conclude that a breakdown of immunity to $N$. brasiliensis can occur in lactating rats; this strongly suggests that the lactating rat is a suitable model for elucidating a possible nutritional basis of breakdown of immunity to parasites. However, sufficient protein intake must be achieved to address the hypothesis that breakdown of immunity to $N$. brasiliensis is sensitive to protein supply.
\end{abstract}

\section{Nippostrongylus brasiliensis: Nutrition: Immunity: Lactating rats}

Animals, including man, are often continuously exposed to infective forms of parasites, and consequently acquire immunity towards most of them (Gray \& Gill, 1993). However, the expression of acquired immunity to parasites can break down during several phases of the host's life. For example, a periparturient breakdown of immunity to a range of parasite species and hosts has been observed, and has long been known to occur in sheep (Taylor, 1935), where it is associated with an increased gastrointestinal nematode burden and excretion of nematode eggs onto the pasture. Periparturient breakdown of acquired immunity is not limited to gastrointestinal nematodes, but has also been observed for protozoa (Lloyd et al. 1983; Xiao \& Herd, 1994) and ectoparasites (James, 1999). However, breakdown of immunity may not necessarily be associated with the periparturient period. For example, type II ostertagiosis has been observed in growing calves at the end of their winter housing period (Berghen et al. 1990). This is associated with the re-emerging of inhibited larvae within the gastrointestinal tract and could thus be considered as a breakdown of the previously acquired immunity to gastrointestinal nematodes. A breakdown of immunity also occurs in ageing animals, including human subjects, who typically show a reduced cellular immune response and delayed secondary immune responses (Chandra, 1989).

These examples of breakdown of immunity may all have a nutritional basis. A recently developed nutrient-partitioning framework puts forward a nutritional basis for periparturient breakdown of immunity (Coop \& Kyriazakis, 1999). Indeed, there is now an increasing body of evidence to support the view that protein supply, in particular, affects the degree of breakdown of immunity to gastrointestinal nematodes in periparturient sheep (Houdijk et al. 2003). Second, it has been suggested that host nutrition in general, and the presence of body reserves in particular, may affect type II ostertagiosis in calves (Houdijk et al. 2001). Last, the ageing-related breakdown of immunity is often concurrent with nutrient deficiencies, and it has been shown that supplementation and nutritional advice to ageing human subjects improves their immune responses in general and their cellular immune responses in particular (Chandra, 1989).

The nutritional basis of breakdown of immunity may best be assessed in a model in which relatively large differences of host nutritional status can be achieved. We chose the rat as our experimental model as it has a substantially elevated 
nutrient requirement during lactation (up to tenfold relative to maintenance), and its lactational response to changes in endogenous and dietary protein supply are increasingly being understood (Jessop, 1997). In addition, rats acquire a relatively strong immunity to the small intestinal nematode Nippostrongylus brasiliensis, and immune rats rapidly expel adult $N$. brasiliensis during a secondary infection (Jarrett et al. 1968). The immune expulsion of $N$. brasiliensis is thought to be mediated mainly through globlet cell hyperplasia and associated mucus production, although mucosal mast cell hyperplasia also occurs (Woodbury et al. 1984; Rothwell 1989; Nawa et al. 1994).

Whilst host lactation delays the expulsion of adult N. brasiliensis during a primary infection (Connan, 1970; Dineen \& Kelly, 1972), we would argue that such models might not be appropriate to assess breakdown of immunity, since they do not represent a degree of a breakdown of a previously acquired immunity. In our view, the most appropriate model to elucidate the nutritional basis of the breakdown of immunity to parasites would be one that exploits a secondary $N$. brasiliensis infection in lactating rats. Therefore, we first hypothesized that a breakdown of immunity to $N$. brasiliensis would occur in lactating rats, and second that the degree of this breakdown of immunity would be sensitive to dietary protein supply.

\section{Materials and methods}

\section{Animals and housing}

Multiparous (second parity) female Sprague-Dawley rats (B\&K Universal Ltd, Hull, UK) were housed in a room regulated at $20-21^{\circ} \mathrm{C}$ with relative humidity $45-65 \%$ and lights on from 08.00 to 20.00 hours. Apart from during mating and for faeces collection during the primary infection (see later), rats were housed in solid-bottomed cages with fresh sawdust provided weekly and a handful of shredded plastic wrapping paper for nesting material from $3 \mathrm{~d}$ before expected parturition until the end of the experiment. The parturition date (day 0) was defined as the morning when parturition was observed to have finished. For mating, forty-eight female rats were placed in wire-bottomed cages with a proven male breeder; mating was confirmed through the presence of a vaginal plug underneath these cages. Four rats were not mated, and these barren rats were used as positive controls (see later). Throughout the experiment, all rats had ad libitum access to fresh water.

\section{Foods}

All rats were given ad libitum access to standard rat chow (B\&K Universal Ltd) until mating was confirmed. Then, rats were given access to experimental foods 1,2 or 3 , which were all calculated to supply $21 \cdot 3 \mathrm{MJ}$ gross energy/ $\mathrm{kg} \mathrm{DM}$ and 60,90 or $210 \mathrm{~g}$ crude protein $(\mathrm{N} \times 6 \cdot 25) / \mathrm{kg}$ DM respectively (see Table 1 ). All mated rats were given ad libitum access to food 3 for the first $10 \mathrm{~d}$ after mating and then to food 1 until parturition. At the same time, the same foods were offered to the barren rats. The barren rats continued to receive food 1 until the end of the experiment,
Table 1. Ingredients and chemical analysis of the experimental foods

\begin{tabular}{lrrr}
\hline & \multicolumn{3}{c}{ Experimental foods* $^{*}$} \\
\cline { 2 - 4 } & 1 & 2 & 3 \\
\hline Ingredients (g/kg fresh wt) & 67 & 93 & 221 \\
Casein & 1 & 1 & 2 \\
DL-Methionine & 372 & 359 & 299 \\
Starch & 186 & 180 & 149 \\
Sucrose & 227 & 219 & 182 \\
Maize oil & 46 & 46 & 46 \\
Maize flour & 104 & 104 & 102 \\
Vitamins and minerals & & & \\
Chemical analysis $(\mathrm{g} / \mathrm{kg}$ DM) & 901 & 903 & 857 \\
DM (g/kg fresh wt) & 68 & 98 & 232 \\
Crude protein $(\mathrm{N} \times 6 \cdot 25)$ & 219 & 207 & 177 \\
Diethyl ether extract & 36 & 38 & 38 \\
Ash & 21.3 & 21.3 & 21.3 \\
Gross energy (MJ/kg DM) $\dagger$ & & & \\
\hline
\end{tabular}

* For allocation of foods 1,2 and 3 to the barren and reproducing rats, see p. 810.

†Based on chemistry tables (Chemical Rubber Company, 2001).

whilst lactating rats were given ad libitum access to either low-protein (LP) food 2 or high-protein (HP) food 3. These lactating rats are hereafter referred to as the LP and HP rats respectively. Table 1 presents the ingredients and the chemical analysis of the experimental foods.

The feeding protocol used during pregnancy has been shown to reduce body protein reserves during the second half of pregnancy; this minimizes endogenous protein supply to the lactating rat host from food 2 (Pine et al. 1994). Hence, this protocol has been used to maximize the degree of protein scarcity for the LP rats during lactation. We could not use lower levels of dietary crude protein content, since levels $<90 \mathrm{~g} / \mathrm{kg}$ DM would have resulted in insufficient intake to support lactation (Jessop, 1997).

\section{Infection}

Before mating, all rats received a primary infection of 1600 third-stage infective larvae $\left(\mathrm{L}_{3}\right)$ of $N$. brasiliensis, which were suspended in $0.5 \mathrm{ml}$ sterile PBS and administered by subcutaneous injection in the hindlimb. The lactating rats were given a secondary infection of 400,800 or $1600 \mathrm{~L}_{3}$ on day 2 and the barren rats received $1600 \mathrm{~L}_{3}$ at the same time.

\section{Experimental design}

The experiment consisted of seven treatments, one control (i.e. the barren rats, $n 4$ ) and six within a $2 \times 3$ factorial combination of dietary protein and level of infection for the lactating rats. The first six rats, whose litter size was standardized to twelve pups, were randomly allocated to these six treatments, and this procedure was repeated seven times to obtain seven replicates for each of the six treatments $(n 7)$. Litter size standardization continued until day 2 , using the pups from six rats with relatively smaller litter sizes. All rats were slaughtered $7 \mathrm{~d}$ post secondary infection, i.e. day 9 for the lactating rats, for the assessment of worm burdens and nematode egg counts in the colon contents (see later). Fig. 1 shows the experimental design. 


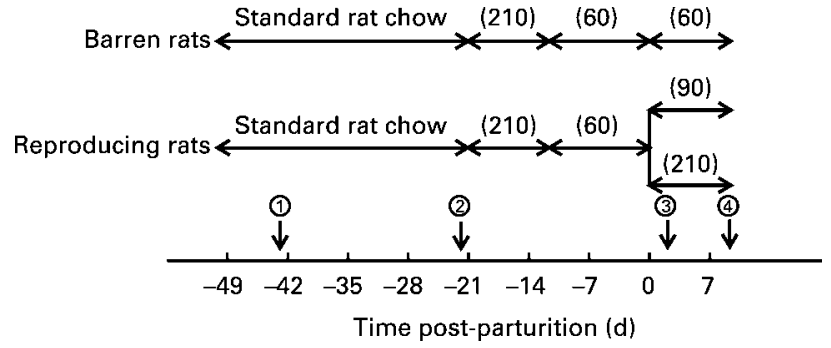

Fig. 1. Experimental design and nutritional protocol. Values in parentheses refer to the crude protein $(\mathrm{N} \times 6.25)$ contents of the experimental diets ( $\mathrm{g} / \mathrm{kg} \mathrm{DM})$. All foods were offered ad libitum and the barren rats were offered these foods at the same time as the reproducing rats relative to parturition (day 0). (1), Primary infection with 1600 infective larvae of Nippostrongylus brasiliensis; (2), mating; (3), secondary infection with either 400,800 or 1600 infective larvae of $N$. brasiliensis; (4), assessment of the small intestinal worm burden and nematode egg count in the colon contents.

\section{Sample collection and measurements}

Body weight and food intake. All rats were weighed regularly from arrival in the animal house onwards to accustom them to the daily weighing, which took place throughout gestation and lactation. Food intake during pregnancy and lactation was measured daily by weighing food jars with refusals and replacing them with filled food jars of known weight. Food samples were taken daily and pooled for the analysis of DM, crude protein (Kjeldahl-N $\times 6.25)$, diethyl ether extract and ash. From the morning of day 0 onwards, pups were counted and weighed, and litter size was standardized. However, from day 2 onwards, litter sizes were not standardized anymore, as changes in litter size could have been the outcome of the secondary infection given at day 2 .

Faecal egg counts. From day 5 to day 12 post primary infection, faeces were collected for the assessment of faecal egg counts. For this purpose, rats were housed overnight in wire-bottomed cages, and their faeces were collected under the cages in trays containing a wet paper towel. Eight to ten faecal pellets were weighed (A) and made into a slurry using $15 \mathrm{ml}$ water. Of this slurry, $7.5 \mathrm{ml}$ was mixed with $50 \mathrm{ml}$ saturated $\mathrm{NaCl}$ solution. Two McMaster counting chambers (FECPAK, Dunedin, New Zealand) were filled with this mixture, and the total number of eggs within the two grids was counted under a microscope (B). The faecal egg count was then calculated as $150 \times(\mathrm{B} / \mathrm{A})$, thus expressed as the number of nematode eggs per $\mathrm{g}$ fresh faeces (eggs $(n) / \mathrm{g}$ faeces). We were not able to collect sufficient amounts of faeces to assess treatment effects on faecal egg count following secondary infection, which was probably primarily due to the high total tract digestibility of the periparturient foods.

Nematode egg counts in the colon contents and worm burden. Rats were sedated and humanely killed by $\mathrm{CO}_{2}$ asphyxiation and dissected to collect the small and large intestine. Large intestinal contents were collected, weighed and assessed for the concentration of nematode eggs as described earlier. Adult nematodes were harvested from the small intestine via baermanization into saline $(9 \mathrm{~g}$ $\mathrm{NaCl} / \mathrm{l}$ ) at $37^{\circ} \mathrm{C}$ using established methods (Kassai, 1982). The nematodes obtained after $3 \mathrm{~h}$ were stored in
$100 \%$ alcohol, pending the assessment of nematode number, sex and developmental stage.

\section{Calculations and statistical analysis}

The total number of nematode eggs in the colon was calculated by multiplying the nematode egg count in the colon contents with the weight of the colon contents. Because of their skewed nature, the colon egg count and worm burden were transformed according to $\log (n+1)$ to normalize data before statistical analysis. These data are reported as back-transformed means with $95 \% \mathrm{CI}$, and were calculated as $10^{\mathrm{a}}-1$ with $\mathrm{a}=\mu+0.5 \times \sigma^{2}$ (Johnson et al. 1988), where $\mu$ is the mean, lower or upper limit of the $95 \%$ CI of the transformed data and $\sigma$ is the standard deviation. We have reported the arithmetic mean values with their standard errors for the non-transformed data.

The hypothesis that breakdown of immunity to parasites occurs in lactating rats was assessed through ANOVA for the effect of reproductive status (barren rats $v$. lactating LP rats, infected with $1600 \mathrm{~L}_{3}$ ) on colon egg count and worm burden (hypothesis 1). The hypothesis that breakdown of immunity to parasites is sensitive to protein supply was assessed through the $2 \times 3$ factorial design on all lactating rats using the factors dietary protein, level of infection and their interaction (hypothesis 2). Observations measured over time (i.e. DM intake) were analysed using these ANOVA within a repeated-measures procedure (split-plot model), where the degrees of freedom from the split-plot were multiplied by the Greenhouse-Geisser $\varepsilon$ factor (Littel et al. 1998). Additional ANOVA was carried out using the factorial model on each time point during lactation and on daily changes when interactions with time were significant. All statistical analyses were performed using Genstat 5 for Windows (release 4.2, service pack 2, 2001; Lawes Agricultural Trust, Rothamsted, Herts., UK).

\section{Results}

Faecal egg count during the primary infection and performance until parturition

The majority of the rats had started to excrete small numbers of nematode eggs in their faeces by $5 \mathrm{~d}$ post primary infection, averaging 42 (range 27-64) eggs/g faeces. Mean faecal egg counts then rapidly increased to peak on day 7 post-infection at 17680 (range 16492-18953) eggs/g faeces. The faecal egg counts then gradually decreased, and all rats stopped excreting nematode eggs by day 12 post-infection.

Following mating, the pregnant rats grew from 297 (SED 3) to 349 (SED 3) g over the first $10 \mathrm{~d}$ of pregnancy, with an average DM intake of 21.3 (SED 0.4) $\mathrm{g} / \mathrm{d}$. Over the same time, the barren rats grew from 297 (SED 3) to 328 (SED 9) $\mathrm{g}$, with an average DM intake of 18.3 (SED 1.3) g/d. The pregnant rats continued to grow to 393 (SED 5) g on day - 1; their DM intake averaged 20.4 (SED 0.4) g/d until day -6 , but then dropped to $1.9(\operatorname{SED} 0 \cdot 3) \mathrm{g} / \mathrm{d}$ on day -1 . Over the same time, the barren rats grew to 339 (SED 12) $\mathrm{g}$, with an average DM intake of 14.1 (SED 0.4) g/d. 


\section{Number of nematode eggs in the colon contents and worm burden following the secondary infection}

Table 2 presents the colon egg count, the total number of adult nematodes and the worm burden composition of the barren rats and the lactating rats. The LP rats, infected with $1600 \mathrm{~L}_{3}$, had significantly more eggs in their colon and adult nematodes than the barren rats. However, worm burden composition did not differ significantly, although the lactating rats tended to have relatively more immature nematodes. Dietary protein and level of infection did not significantly affect the colon egg count of the lactating rats. Although there was not a formally significant interaction between dietary protein and level of infection, the colon egg count tended to increase, with an increased level of infection for the LP rats $(P=0.025)$, but not for the HP rats $(P=0 \cdot 89)$. Dietary protein did not affect the total number of adult nematodes of the lactating rats, but LP rats had a significantly greater \% female worms than the HP rats. The total number of adult nematodes significantly increased with the level of infection and the rats infected with 800 larvae tended to have relatively more immature larvae than those infected with 400 or 1600 larvae.

\section{Performance during the secondary infection}

Fig. 2 shows the DM intake of the barren rats and the lactating rats. The DM intake of the barren rats was relatively constant, but was temporarily reduced following the secondary infection $(P<0.001)$. Time interacted with dietary protein for the lactating rats $(P<0.001)$; LP rats had smaller DM intakes than HP rats from day 1 onwards and this effect increased in size over time. Time also interacted with level of infection $(P=0 \cdot 031)$; between day 3 and day 7 , the DM intake of the rats infected with 800 larvae was greater than that of the rats infected with 1600 larvae $(P=0.048)$, with that of the rats infected with 400 larvae being intermediate. However, from day 7 onwards, the DM intake of the rats infected with 1600 larvae tended to be lower than that of the other two groups $(P=0.085)$. The three-way interaction between time, dietary protein and level of infection was not significant for the DM intake $(P=0.63)$.

At parturition, mean rat body weight was 307 (SED 4) g, mean litter size was 12.2 (SED 0.2) pups and mean litter weight was 61.1 (SED 1.4) g. A mean litter size of 11.8 (SED 0.1) pups was achieved on day 2. Thereafter, the mean number of pups reduced gradually over time to 10.0 (SED 0.4 ) on day 9 , which was not affected by dietary protein $(P=0.65)$, level of infection $(P=0.91)$ or their interaction $(P=0.97)$. The effects of dietary protein on DM intake were reflected in body-weight gain and litter gain. The LP and HP rats gained -6.8 and $2.0 \mathrm{~g} / \mathrm{d}$ (SED $0.83, P<0.001$ ) respectively and their litters gained respectively 1.5 and $11.9 \mathrm{~g} / \mathrm{d}$ (SED $1.34, P<0.001$ ). However, body-weight gain and litter gain were not affected by level of infection $(P=0.78$ and $P=0.97$ respectively) and the interaction between dietary protein and level of infection $(P=0.98$ and $P=0.86$ respectively).

\section{Discussion}

In the present study, we investigated whether a breakdown of immunity to $N$. brasiliensis occurs in lactating rats and whether this breakdown of immunity would be sensitive to protein supply. We considered changes in the number of adult nematodes in the small intestine and the number of nematode eggs in the colon content to be the result of changes in the degree of expression of immunity to

Table 2. Number of nematode eggs in the colon and number of adult nematodes and worm burden composition of barren rats and lactating rats secondarily infected with Nippostrongylus brasiliensis third-stage larvae*

\begin{tabular}{|c|c|c|c|c|c|c|c|c|c|}
\hline $\begin{array}{l}\text { Reproductive } \\
\text { status }\end{array}$ & $\begin{array}{c}\text { Dietary CP } \\
(\mathrm{N} \times 6 \cdot 25 ; \mathrm{g} / \mathrm{kg} \mathrm{DM})\end{array}$ & $\begin{array}{c}\text { Level of } \\
\text { infection }\left(n \mathrm{~L}_{3}\right)\end{array}$ & \multicolumn{2}{|c|}{$\begin{array}{l}\text { Number of nema- } \\
\text { tode eggs in the } \\
\text { colon } \times 1000\end{array}$} & \multicolumn{2}{|c|}{$\begin{array}{l}\text { Number of adult } \\
\text { nematodes }\end{array}$} & \multicolumn{3}{|c|}{ Worm burden composition } \\
\hline Barren & 60 & 1600 & 0.4 & $0 \cdot 1,1 \cdot 8$ & 12 & 8,20 & 45 & 55 & 0 \\
\hline \multirow[t]{2}{*}{ Lactating } & 90 & 1600 & $9 \cdot 8$ & $5 \cdot 7,16 \cdot 8$ & 264 & 161,433 & 37 & 61 & 2 \\
\hline & & 400 & $2 \cdot 3$ & $1 \cdot 2,4 \cdot 4$ & 47 & 32,68 & 35 & 61 & 3 \\
\hline \multirow[t]{3}{*}{ Lactating } & 210 & 1600 & $4 \cdot 7$ & $2 \cdot 9,7 \cdot 7$ & 252 & 162,390 & 46 & 53 & 1 \\
\hline & & 800 & $4 \cdot 1$ & $2 \cdot 3,7 \cdot 3$ & 96 & 61,151 & 46 & 48 & 6 \\
\hline & & 400 & $3 \cdot 2$ & $2 \cdot 5,4 \cdot 3$ & 63 & 38,103 & 38 & 58 & 4 \\
\hline SED & & & & & & & $6 \cdot 8$ & $7 \cdot 1$ & $3 \cdot 8$ \\
\hline \multicolumn{10}{|c|}{$\begin{array}{l}\text { Statistical significance of effect (ANOVA): } P \\
\text { Hypothesis } 1 \dagger\end{array}$} \\
\hline \multicolumn{10}{|c|}{ Hypothesis $2 \dagger$} \\
\hline Protein & & & 0.76 & & 0.62 & & 0.012 & 0.046 & 0.37 \\
\hline Level of $i$ & & & 0.23 & & 0.002 & & 0.51 & 0.66 & 0.062 \\
\hline Protein $\times$ & fection & & 0.25 & & 0.89 & & 0.23 & 0.49 & 0.65 \\
\hline
\end{tabular}

$C P$, crude protein; $L_{3}$, third-stage infective larvae.

${ }^{*}$ For details of foods and procedures, see Table 1 and p. 810.

†See p. 811. 

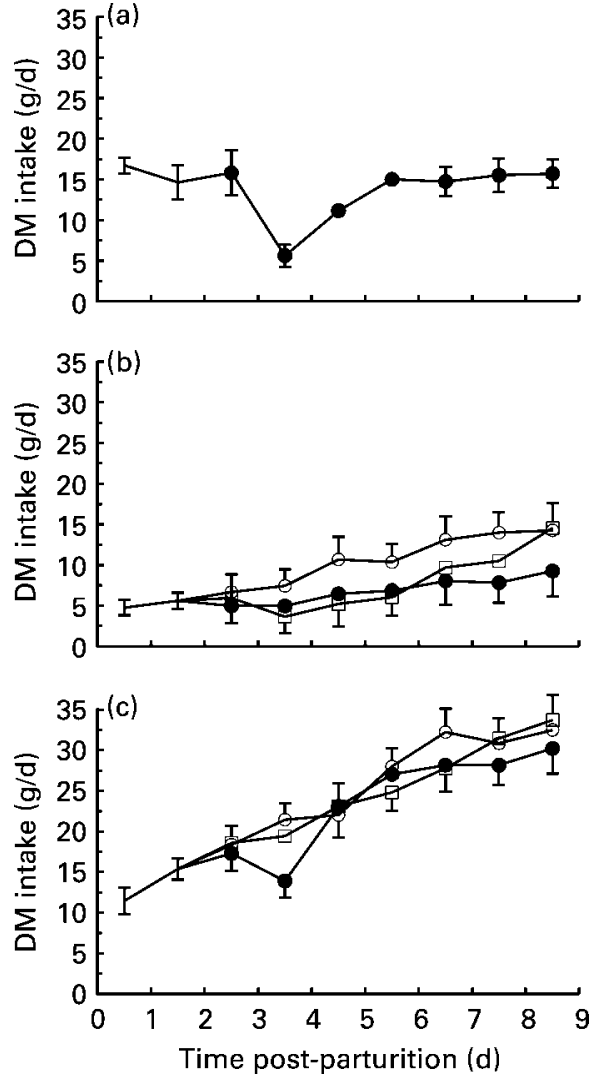

Fig. 2. DM intake of barren rats offered foods with $60 \mathrm{~g}$ crude protein $(\mathrm{N} \times 6.25) / \mathrm{kg} \mathrm{DM}(\mathrm{a})$, lactating rats offered foods with $90 \mathrm{~g}$ crude protein $/ \mathrm{kg}$ DM (b) and lactating rats offered foods with $210 \mathrm{~g}$ crude protein $/ \mathrm{kg}$ DM (c). Rats were secondarily infected with 400 (口), 800 (०) or 1600 (•) Nippostrongylus brasiliensis infective third-stage larvae on day 2 post-parturition; the barren rats were infected at the same time. For details of foods and procedures, see Table 1 and p. 810. Values are means with their standard errors shown by vertical bars (four for barren rats and seven for lactating rats).

$N$. brasiliensis. Hence, the parasitological observations, i.e. the worm and egg counts, would provide the initial information to assess the success of the model, as they provide the ultimate measure on how the host copes with the challenge. Therefore, at this stage, direct immune responses were not assessed, but these will follow in future studies, pending successful establishment of the model.

With the exception of one single study, all published work on $N$. brasiliensis infections in lactating rats have reported primary infections, and these studies indicate that host lactation results in a delayed expulsion of the adult nematodes (Connan, 1970; Dineen \& Kelly, 1972; Brown et al. 1981). However, Connan (1972) reported a study on a secondary infection with $N$. brasiliensis in lactating rats; lactating and barren rats carried on averaged 29.0 and 4.3 adult $N$. brasiliensis respectively following a secondary infection with $1500 \mathrm{~L}_{3}$. Although this sixfold difference points in the direction of a breakdown of immunity to $N$. brasiliensis in lactating rats, he considered that the lactating rats in his study were still very immunocompetent, since he retrieved 318 adult $N$. brasiliensis from barren rats following a primary infection of $1500 \mathrm{~L}_{3}$.
The latter is very close to the back-transformed mean value of 264 adult $N$. brasiliensis recovered in our present experiment from the lactating LP rats; this number corresponded to an arithmetic mean of 309 worms. Hence, our present results support the view that lactating rats show a breakdown of immunity to $N$. brasiliensis. In contrast to Connan's conclusion (1972), this strongly suggests that lactating rats can be used as a model to systematically elucidate a possible nutritional basis for breakdown of immunity to parasites.

There is an increasing body of evidence that breakdown of immunity to parasites in periparturient small ruminant animals is sensitive to protein supply (Houdijk et al. 2001, 2003). However, in contrast to the expectation, protein supply did not greatly affect the degree of breakdown of immunity to $N$. brasiliensis in the present experiment. The increased supply of protein did not affect the number of nematode eggs in the colon, although there was a tendency for an increased number of nematode eggs in the colon at the higher levels of infection for the LP rats, but not for the HP rats. This observation could have been substantiated through repeated measures on faecal egg counts and assessment of daily nematode egg excretion during the secondary infection, but the highly digestible foods did not allow collection of sufficient volumes of faeces for this purpose. Sufficient volumes of faeces may be collected through inclusion of non-fermentable fibre in the foods, e.g. purified cellulose.

The increased supply of protein did not affect the number of adult nematodes in the small intestine. However, compared with the HP rats, the LP rats had worm burdens that consisted of relatively more female worms and less male worms. It has been shown that female adult nematodes are expelled at a higher rate than male adult nematodes (Africa, 1931; Jarrett et al. 1968), and that rats infected solely with female adult $N$. brasiliensis develop a stronger immunity than rats infected with male worms (Ogilvie, 1965). Taken together, these observations suggest that expression of immunity may be stronger towards female $N$. brasiliensis than towards males. Hence, the larger proportion of female worms observed in the LP rats could therefore have been due to some degree of reduced expression of immunity, specifically directed to female $N$. brasiliensis.

Since female worms are longer and heavier than male worms (Kassai, 1982), it would be reasonable to assume that the mean worm length and weight of the worm burdens in the LP rats was larger than in the HP rats. For abomasal infections in sheep, it has been suggested that hosts aim to control worm mass rather than worm number, since longer and heavier worms may cause more damage to the host (Stear et al. 1999). If such arguments hold for small intestinal infections as well, then having a worm burden with shorter and lighter worms would have been beneficial to the HP rats compared with the LP rats.

Protein intake of the barren rats averaged 0.8 (SED 0.03) $\mathrm{g} / \mathrm{d}$, which was similar to the protein intake achieved by the lactating LP rats. However, because of the absence of lactation and hence much lower protein requirement (National Research Council, 1995), the protein intake of the barren rats was more than sufficient to satisfy their 
protein requirements, i.e. protein supply was not scarce. Under such non-scarce conditions, expression of immunity to parasites was not expected to be compromised (Coop \& Kyriazakis, 1999), and our present results support this view.

The nutritional protocol we used has been previously developed and applied in our laboratory (Pine et al. 1994), and we observed very similar DM intake during gestation and litter size and litter weight at birth. However, DM intake during lactation in the current experiment was approximately $20 \%$ lower than that in the aforementioned study. Consequently, crude protein $(\mathrm{N} \times 6.25)$ intake of the HP rats averaged 5.3 (SED 0.19) g/d, which is approximately $25 \%$ lower than the protein requirements suggested for lactating rats (National Research Council, 1995). Hence, protein intake achieved during lactation was likely to be scarce, also for the HP rats. This may be the reason why the increased protein supply for the HP rats did not result in a reduced breakdown of immunity to $N$. brasiliensis, since the latter would only be expected to occur when an increased protein supply overcomes protein scarcity (Coop \& Kyriazakis, 1999; Houdijk et al. 2001). Under the current level of DM intake, the second hypothesis could only have been properly addressed at dietary crude protein concentrations in the order of $300 \mathrm{~g} / \mathrm{kg} \mathrm{DM}$.

In conclusion, lactating rats offered LP foods and with a high lactational burden exhibit a breakdown of immunity to $N$. brasiliensis, and may thus be used as a model to elucidate the nutritional basis of breakdown of immunity to parasites. However, sufficient intake of protein must be achieved to properly address the hypothesis that the breakdown of immunity to $N$. brasiliensis is sensitive to protein supply.

\section{Acknowledgements}

We wish to thank Graeme Allan, John Moore, John Verth, John Tweedy, Vicky Brown and Sheena Boath for their assistance in taking care of the animals, sampling, and analytical and parasitological support. The Scottish Agricultural College and the Moredun Research Institute receive support from the Scottish Executive, Environment and Rural Affairs Department.

\section{References}

Africa CM (1931) Studies on the host relations of Nippostrongylus muris. J Parasitol 18, 1-13.

Berghen P, Dorny P, Hilderson H, Vercruysse J \& Hollanders W (1990) Observations on parasitic gastroenteritis and parasitic bronchitis in calves over two grazing seasons. Vet Rec 127, 426-430.

Brown PJ, Charleypoulin J \& Pery P (1981) Nippostrongylus brasiliensis infection in the rat. 2 . A comparison of production of antibodies in bile and serum by baby rats, lactating rats and adult rats. Vet Immunol Immunopathol 2, 475-482.

Chandra RK (1989) Nutritional regulation of immunity and risk of infection in old age. Immunology 67, 141-147.

Chemical Rubber Company (2001) Handbook of Chemistry and Physics, 82nd ed. London: CRC Press.
Connan RM (1970) The effect of host lactation on the self-cure of Nippostrongylus brasiliensis in rats. Parasitology 61, 27-33.

Connan RM (1972) The effect of host lactation on a second infection of Nippostrongylus brasiliensis in rats. Parasitology 64, 229-233.

Coop RL \& Kyriazakis I (1999) Nutrition-parasite interaction. Vet Parasitol 84, 187-204.

Dineen JK \& Kelly JD (1972) The suppression of rejection of Nippostrongylus brasiliensis in lactating rats: the nature of the immunological defect. Immunology 22, 1-12.

Gray GD \& Gill HS (1993) Host genes, parasites and parasitic infections. Int $J$ Parasitol 23, 485-494.

Houdijk JGM, Jessop NS \& Kyriazakis I (2001) Nutrient partitioning between reproductive and immune functions in animals. Proc Nutr Soc 60, 515-525.

Houdijk JGM, Kyriazakis I, Jackson F, Huntley JF \& Coop RL (2003) Is the allocation of metabolisable protein prioritised to milk production rather than to immune functions in Teladorsagia circumcincta infected lactating ewes? Int $J$ Parasitol 33, 327-338.

James PJ (1999) Do sheep regulate the size of their mallophagan louse populations? Int J Parasitol 29, 869-875.

Jarrett EEE, Jarrett WFH \& Urquhart GM (1968) Quantitative studies on the kinetics of establishment and expulsion of intestinal nematode populations in susceptible and immune hosts. Nippostrongylus brasiliensis in the rat. Parasitology 58, 625-639.

Jessop NS (1997) Protein metabolism during lactation. Proc Nutr Soc 56, 169-175.

Johnson NL, Kotz S \& Balakrishnan N (1988) Continuous Univariate Distributions, vol. 1, 2nd ed. Boston, MA: PWSKENT.

Kassai T (1982) Handbook of Nippostrongylus brasiliensis (nematode). Budapest: Commonwealth Agricultural Bureaux.

Littel RC, Henry PR \& Ammerman CB (1998) Statistical analysis of repeated measures data using SAS procedures. J Anim Sci 76, $1216-1231$.

Lloyd S, Amerasinghe PH \& Soulsby EJL (1983) Periparturient immunosuppression in the bitch and its influence on infection with Toxocara canis. J Small Anim Pract 24, 237-247.

National Research Council (1995) Nutrient Requirements of Laboratory Animals, 4th ed. Washington, DC: National Academy Press.

Nawa Y, Ishikawa N, Tsuchiya K, et al. (1994) Selective effector mechanisms for the expulsion of intestinal helminths. Parasite Immunol 16, 333-338.

Ogilvie BM (1965) Role of adult worms in immunity of rats to Nippostrongylus brasiliensis. Parasitology 55, 325-335.

Pine AP, Jessop NS \& Oldham JD (1994) Maternal protein reserves and their influence on lactational performance in rats. Br J Nutr 71, 13-27.

Rothwell TLW (1989) Immune expulsion of parasitic nematodes from the alimentary tract. Int J Parasitol 19, 139-168.

Stear MJ, Strain S \& Bishop SC (1999) How lambs control infection with Ostertagia circumcincta. Vet Immunol Immunopathol 72, 213-218.

Taylor EL (1935) Seasonal fluctuation in the number of eggs of trichostrongylid worms in the faeces of ewes. J Parasitol 21, $175-179$.

Woodbury RG, Miller HRP, Huntley JF, Newlands GFJ, Palliser AC \& Wakelin D (1984) Mucosal mast cells are functionally active during spontaneous expulsion of intestinal nematode infections in rat. Nature 312, 450-452.

Xiao L \& Herd RP (1994) Epidemiology of equine Cryptosporidium and Giardia infections. Equine Vet J 26, 14-17. 